\title{
Congenital urethral dilatation in cattle calves: Diagnosis and surgical intervention
}

\author{
Magda Mahmoud Ali ${ }^{1}$, Kamal Hany Hussein ${ }^{1,2}$, Ahmed Sadek ${ }^{1}$ and Abdelbaset Eweda Abdelbaset ${ }^{3,4}$
}

1. Department of Surgery, Anesthesiology and Radiology, Faculty of Veterinary Medicine, Assiut University, Assiut 71526 , Egypt; 2. Department of Surgery, College of Veterinary Medicine, Kangwon National University, Chuncheon, Gangwon 24341, South Korea; 3. Department of Animal Medicine, Clinical Laboratory Diagnosis, Faculty of Veterinary Medicine, Assiut University, Assiut 71526, Egypt; 4. National Research Center for Protozoan Diseases, Obihiro University of

Agriculture and Veterinary Medicine, 2-13 Inada-cho, Obihiro, Hokkaido 080-8555, Japan.

Corresponding author: Kamal Hany Hussein, e-mail: kamalhussein1986@gmail.com

Co-authors: MMA: magdaali70@aun.edu.eg, AS: ahmed.abdelrahiem@vet.au.edu.eg, AEA: abdelbaset2006@hotmail.com Received: 16-10-2019, Accepted: 27-12-2019, Published online: 11-02-2020

doi: www.doi.org/10.14202/vetworld.2020.261-265 How to cite this article: Ali MM, Hussein KH, Sadek A, Abdelbaset AE (2020) Congenital urethral dilatation in cattle calves: Diagnosis and surgical intervention, Veterinary World, 13(2): 261-265.

\begin{abstract}
Background and Aim: Congenital anomalies of the urinary system are common affections in ruminants. Dilatation of the pelvic urethra is one of these affections in which the pelvic urethra dilated than normal diameter. This study aimed to explain the diagnosis and surgical treatment of urethral dilatation in cattle calves.
\end{abstract}

Materials and Methods: Twenty-three bull calves (2-7 months old) were presented with a history of stranguria, tenesmus, and straining. Diagnosis of urethral dilatation was relied on the case history and clinical examination and was confirmed using survey and contrast radiography, ultrasonography, and biochemical tests. Treatment was done by urethrostomy under the effect of local infiltration analgesia.

Results: Physical examination revealed the presence of an oval, firm, and painless swelling at the perineal region, starting just below the anus and extended to the base of the scrotum. The owners reported that the initial swelling size and severity of symptoms increased with the progress of animal age. Biochemical findings revealed non-significant changes in blood urea nitrogen and creatinine levels. Radiographic findings showed an oval radiopaque mass. However, a well-demarcated structure with acoustic enhancement was detected on ultrasonographic examination. Urethrostomy resulted in a successful outcome of all cases.

Conclusion: Depending on these findings, ultrasonography is the most reliable diagnostic tool and urethrostomy is the intervention of choice with acceptable results for diagnosis and treatment of urethral dilatation in cattle calves, respectively.

Keywords: congenital anomalies, urethral dilatation, urethrostomy.

\section{Introduction}

Urogenital congenital defects were reported in ruminants with variations in the frequency of occurrence [1-3]. The abnormalities of the urinary system are more common in small ruminants than in large ruminants and more frequently in goats than in sheep [4]. The male urethra consists of pelvic and extrapelvic parts, connecting the urinary bladder to the penis [2].

Congenital anomalies involving the urethra of cattle have been described including dilatation, hypospadia, epispadia, ectopic urethra, imperforate urethra, and deformities of the urethral external [5-11]. Congenital urethral dilatation was reported in kids [12-15] and bull calves [8,16-18]. However, still, there are limited reports about the urethral dilatation diagnosis techniques, although the rate of urethral dilatation incidence started to increase.

Copyright: Ali, et al. Open Access. This article is distributed under the terms of the Creative Commons Attribution 4.0 International License (http://creativecommons.org/licenses/by/4.0/), which permits unrestricted use, distribution, and reproduction in any medium, provided you give appropriate credit to the original author(s) and the source, provide a link to the Creative Commons license, and indicate if changes were made. The Creative Commons Public Domain Dedication waiver (http://creativecommons.org/ publicdomain/zero/1.0/) applies to the data made available in this article, unless otherwise stated.
This study aimed to explain the diagnosis and surgical treatment of urethral dilatation in cattle calves.

\section{Materials and Methods}

\section{Ethical approval and Informed consent}

All animal procedures were conducted in compliance with the guidelines approved by our Institutional Animal Care and Use Committee (Assiut University, Egypt). All procedures were performed with the owners' consent.

\section{Animals, case history, and clinical examination}

This study was conducted on 23 cattle calves aged from 2 to 7 months, admitted to the Veterinary Teaching Hospital, Faculty of Veterinary Medicine, Assiut University, Egypt, from March 2010 to March 2019. Calves had a history of progressive development of swelling in the perineal region that appeared a few days after birth accompanied by stranguria, tenesmus, dribbling of urine, and straining. All animals underwent a thorough clinical examination according to Radostits et al. [7]. General condition of the animal, rectal temperature, heart rate, and respiratory rate as well as shape, size, and consistency of these swellings was examined. 


\section{Radiographic and ultrasonographic examination}

Survey radiography was applied to the perineal region in latero-lateral projection. Positive-contrast urethrography was performed under the effect of xylazine $\mathrm{HCl}$ 2\% (Xyla-Ject ${ }^{\circledR}$, ADWIA Co., Egypt) in a dose of $0.1 \mathrm{mg} / \mathrm{kg}$ body weight and local application of Xylocaine $\mathrm{HCl} 2 \%$ jelly (AstraZeneca Co., Egypt) on a French Foley urinary catheter. After insertion of the catheter into the distal urethra to the level of the proximal sigmoid flexure, the urethral lumen was compressed manually at the base of the catheter. The urine in the swelling was aspirated and replaced with $120 \mathrm{ml}$ of sodium iothalamate (Conray 400, Mallinckrodt Inc., St. Louis, Missouri, USA) diluted to a concentration of $200 \mathrm{mg}$ iodine $/ \mathrm{ml}$.

Ultrasonographic examination of the swellings using 8-10 MHz linear transducer (Pie medical Aquila Pro Vet, Maastricht, Holland) was performed for 14 cases in the standing position and without the use of anesthetics.

\section{Biochemical analysis}

Whole blood samples were collected from the jugular vein of calves in $5 \mathrm{~mL}$ plain Vacutainer tubes. The samples were centrifuged, for $15 \mathrm{~min}$ at $1500 \mathrm{~g}$ speed, and sera were then harvested and preserved at $-20^{\circ} \mathrm{C}$ until used. Serum levels of creatinine and blood urea nitrogen (BUN) were measured through commercial test kits (Spinreact, Girona, Spain), using ultraviolet (UV) spectrophotometer (Optizen 3220 UV, Mecasys Co. Ltd., Korea).

\section{Surgical intervention}

The perineal region was prepared for aseptic surgery by clipping, shaving, and scrubbing with betadine solution. After local infiltration analgesia using lidocaine $\mathrm{HCl}$ 1\% (Debocaine $^{\circledR}$, El-Nasr Pharm Chemicals Co., Egypt), an elliptical skin excision was performed at the lower part of the swelling. The subcutaneous tissue was dissected followed by incision of the urethra. After evacuation of the swelling contents and flushing with normal saline $0.9 \%$, a Foley catheter was inserted into the urethra and was directed toward the urinary bladder to ensure the patency of the urethral lumen and absence of other causes of urethral obstruction such as urethral calculi. A permanent fistula was created by suturing of the urethral mucosa to the skin using non-absorbable silk suture material No.1 (Silk ${ }^{\circledR}$, USP, England) in a simple interrupted pattern.

\section{Post-operative care}

A mixture of penicillin $G$ and streptomycin (Vetrocin $^{\circledR}$, El-Nasr Pharm Chemicals, Egypt) was administered intramuscularly every $12 \mathrm{~h}$ for a period of 5 days. Follow-up of all cases was done for 3 months.

\section{Statistical analysis}

Data of biochemical analysis are expressed as mean \pm standard deviation. The statistical analysis was performed using the SPSS 19.0 software (Chicago, IL, USA). Student's t-test was used to identify significant differences.

\section{Results}

\section{Clinical findings}

Clinical examination revealed normal rectal temperature, pulse rate, and respiratory rate in all cases except in two calves that were feverish with abnormal pulse and respiratory rates. The swelling was fluctuant, painless, and extended on the perineal region, from just below the anus till the base of scrotum (Figure-1a). The size and consistency (tensed or relaxed) varied according to the filing status of the swelling. Bulging of the swelling and pulsation of the proximal urethra were observed in all cases during urination. Urine dripped passively from the penis for several minutes after the urethral pulsation had ceased. Direct pressure on the swelling resulted in a further release of urine. Rectal examination was possible in two cases and revealed moderate-to-severe distension of the urinary bladder. Exploratory puncture of the swelling was done under complete aseptic conditions and yielded a clear uriniferous fluid in all cases (Figure-1b). In two cases, the aspirate was turbid and mixed with pus while it was mixed with clotted blood in one case (Figure-2).

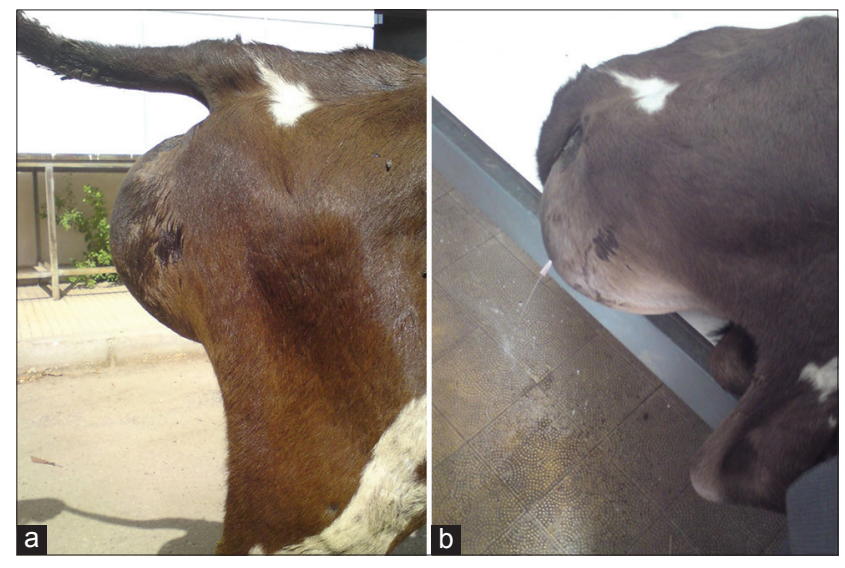

Figure-1: (a) The urethral dilatation appears as an oval swelling in the perineal region. (b) Exploratory puncture of the swelling yielded a clear uriniferous fluid in 12 cases.

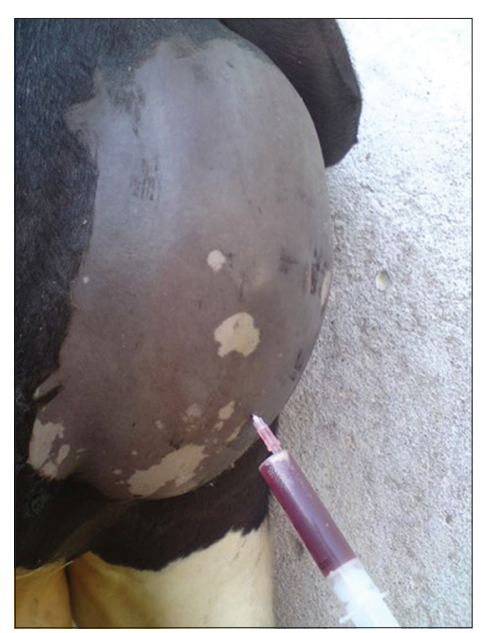

Figure-2: Aspiration of the swelling content revealed the presence of clotted blood in one case. 


\section{Biochemical findings}

BUN and creatinine levels were not significantly different in calves with urethral dilatation compared to healthy calves. The measured values are recorded in Figure-3.

\section{Radiographic and ultrasonographic findings}

In positive-contrast urethrogram, a radiopaque oval mass was observed just under the anus (Figure-4a). Ultrasonographic examination revealed the presence of an anechoic to hypoechoic homogenous structure with a well-demarcated wall and acoustic enhancement (Figure-4b). The connection between the diverticulum and the urinary bladder appeared as a narrow anechoic area with a demarcated wall. Variation in the echogenicity with the appearance of hyperechoic crystals was usually attributed to the variation in the concentration of the urine and concurrent diseases of the urinary tract as in cystitis. Thickening of the urethral wall was evident in all cases.

Surgical treatment by urethrostomy resulted in a successful outcome in 21 cases (Figure-5). In two cases, the wound of the urethral fistula closed due to granulation tissue and pus formation; therefore, the swelling occurred again and reoperation of the urethral lumen was required (Figure-6).

\section{Discussion}

Urethral dilatation is one of the urinary tract problems that may be either acquired due to obstruction of the

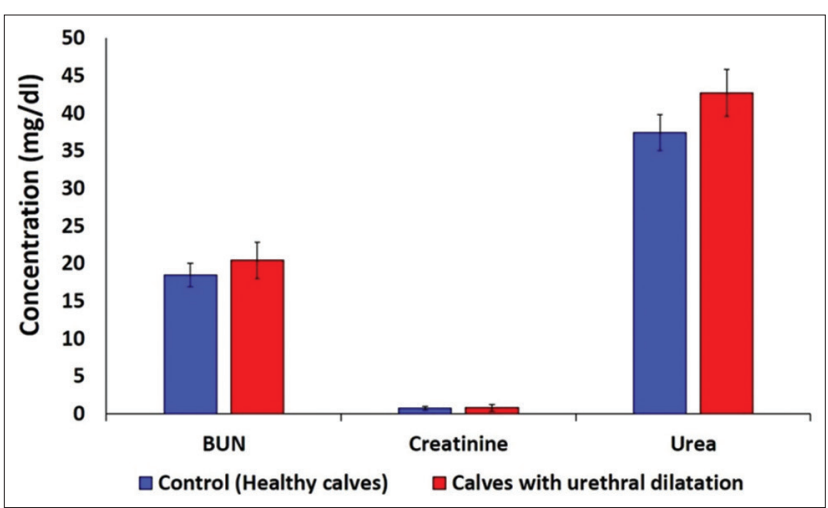

Figure-3: Biochemical analysis of blood urea nitrogen, creatinine, and urea in calves suffered from urethral dilatation compared to healthy calves.

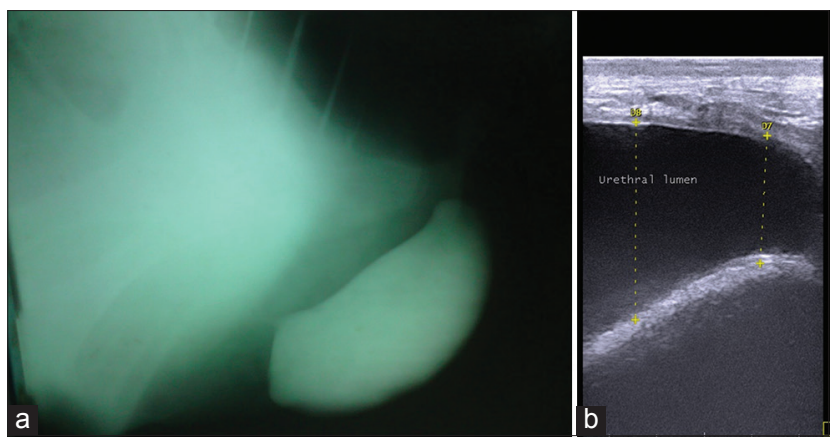

Figure-4: (a) Positive-contrast urethrogram shows a radiopaque oval mass which can easily define from surrounding soft tissues. (b) Ultrasonographic examination revealed the presence of an anechoic to hypoechoic homogenous structure with well-demarcated wall. urethra or congenital due to hereditary factors [19-22]. Bacterial urethritis and surgical manipulation could also result in partial obstruction of a part of the urethra which predisposes to urethral dilatation in other parts $[12,17]$. In our study, the main cause of urethral dilatation was congenital as it was observed a few days after birth. The previous studies have reported that urethral dilatation occurs sporadically and is recognized easily, but sometimes it is neither so easily repaired nor the outcome of its surgical correction has been fully discussed $[5,12,16,19,20,23,24]$. In our study, the affection was easily recognized from the owner's history that was appearance of an oval mass in the perineal region interfering with urination few days after birth. However, the urethral swelling should be differentiated from other conditions of the urethra including hematoma or abscess, congenital anomaly of urinary tract, and pathological urethral dilatation [17,25]. In the present work, differential diagnosis was performed by exploratory puncture, biochemical analysis, survey and contrast radiography, and ultrasonography. Sindak
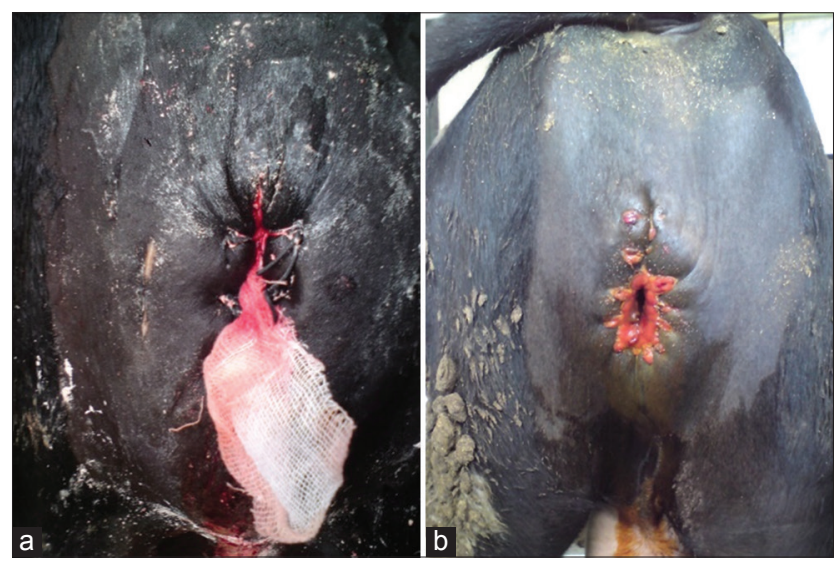

Figure-5: Surgical treatment by urethrostomy resulted in a successful outcome in 21 cases.

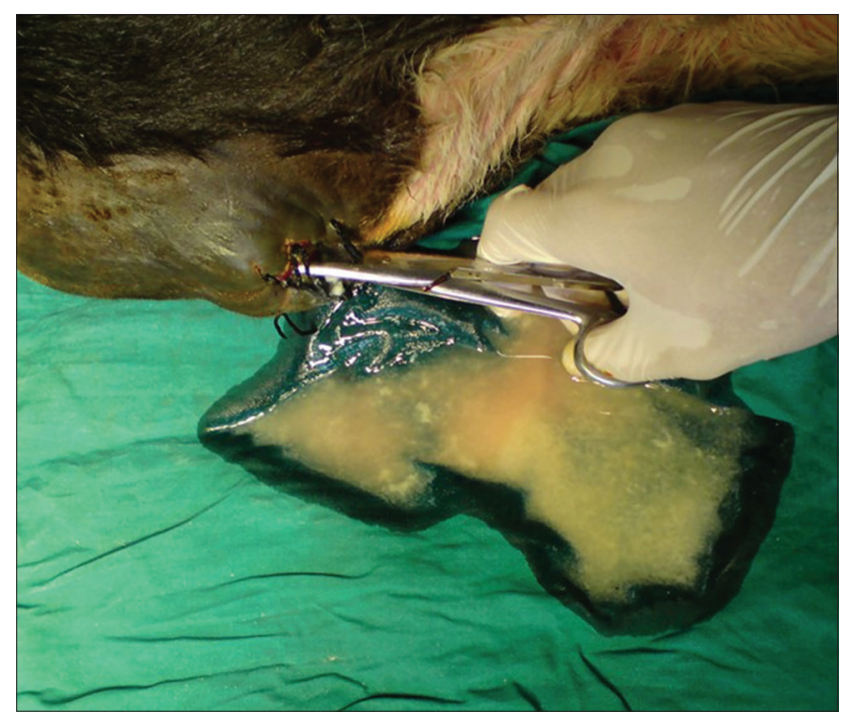

Figure-6: Complication after performing the urethral fistula. The wound closed due to granulation tissue with pus formation; therefore, the swelling occurred again and reoperation was required. 
et al. [25] confirmed the diagnosis of urethral dilatation by exploratory puncture of the swelling, while positive-contrast urethrogram was used by Anderson et al. [16] to exclude the rupture of the urethra at the level of the ischial arch and a congenital anomaly of the urinary tract. Ultrasound provided more information needed for differential diagnosis of urethral dilatation compared to other techniques used in our study. The variation in echogenicity of the swelling contents facilitated the exclusion of other affections. Ultrasound was non-invasive and did not require the use of anesthesia or special preparation for the patient [26]. It could be used in standing or recumbent position and could be easily used in field conditions. Contrary to radiography, ultrasound does not involve the use of ionizing radiation. Therefore, it is safe for patients and operators during investigation $[27,28]$. In addition, Braun mentioned that it is rarely necessary to anesthetize animals for ultrasonography [27].

BUN and creatinine can be used as an index of azotemia due to its simplicity in assessment [7]. In this study, the authors found that BUN and creatinine levels were not significantly different before and after the surgery. This may be attributed to the fact that congenital urethral dilatation did not interfere with urine flow and may be associated only with urine accumulation at the dilated part of the urethra. Animals with urethral dilatation are usually suffered from bacterial urethritis and/ or cystitis as a result of accumulation of urine in the swelling for a long period which facilitates the ascending infection $[16,29]$. In addition, rupture of the urinary bladder may ensue if the condition was associated with aplasia of the penis [30-33]. Due to these complications, surgical intervention in these cases is required $[12,32]$. In the current study, surgical treatment by urethrostomy resulted in a successful outcome in 21 cases while stricture, reobstruction, and presence of little amount of pus were recorded in two cases 3 weeks post-operative.

\section{Conclusion}

Urethral dilatation is one of the urogenital anomalies affecting cattle calves. Differential diagnosis for such condition is the best done with ultrasonography compared to other diagnostic techniques as radiography. Surgical treatment by performing a permanent urethrostomy was shown to be a successful technique, which helps to save animal life and to improve the animal's marketability.

\section{Authors' Contributions}

MMA contributed to the conception, design, provision of field sample, and drafting of the manuscript. AS and AEA contributed to the provision of field samples and drafting the manuscript. KHH contributed to the conception, design, provision of field sample, data analysis and interpretation, and wrote and approved the final draft of the manuscript. All authors contributed to the final editing and approval of the manuscript.

\section{Acknowledgments}

The authors would like to thank the members of the Department of Surgery, Anesthesiology and Radiology in Faculty of Veterinary Medicine, Assiut University, for their help and cooperation. The authors did not receive any funds for this study.

\section{Competing Interests}

The authors declare that they have no competing interests.

\section{Publisher's Note}

Veterinary World remains neutral with regard to jurisdictional claims in published institutional affiliation.

\section{References}

1. Magda, M.M. and Youssef, H. (2007) Surgical Management of Congenital Malformations in Ruminants. Priory Lodge Education Limited, United Kingdom.

2. Vijayanand, V., Gokulakrishnan, M. and Rajasundaram, R. (2009) Multiple congenital defects in a newborn calf-a case report. Tamilnadu J. Vet. Anim Sci., 5(4): 161-163.

3. Sylla, L., Crociati, M., Pistolesi, A., Pisello, L., Caivano, D. and Angeli, G. (2019) Urethrostomy in an Alpine kid secondary to congenital penile urethral diverticulum. Large Anim. Rev., 25(4): 153-156.

4. Rousseaux, C. and Ribble, C. (1988) Developmental anomalies in farm animals: II. Defining etiology. Can. Vet. J., 29(1): 30-40.

5. Geccekp, M. and Alkan, I. (2000) Congenital urethral dilatation in a male Montaphon calf. Isr. J. Vet. Med., 55(1): 10-12.

6. Hunt, R. and Allen, J.D. (1989) Treatment of patent urachus associated with a congenital imperforate urethra in a calf. Cornell Vet., 79(2): 157-160.

7. Radostits, O., Gay, C., Blood, D. and Hinchcliff, K. (2000) A Textbook of the Diseases of Cattle, Sheep, Pigs, Goats and Horses. Saunders Ltd., United Kingdom. p366-367.

8. Weaver, A., Johnson, G. and Hill, J. (1992) Congenital megalourethra in a male Charolais calf. Can. Vet. J., 33(4): 270-272.

9. Nair, S., Devanand, C., Anoop, S. and Kumar, H.H.V. (2017) Surgical management of patent urachus and congenital urethral stricture in a calf: A case report. Indian Vet. J., 94(9): 49-50.

10. Phiri, A., Sakala, M. and Soko, J. (2016) Management of atresia ani with concurrent hypospadias and penile aplasia in a 3-day-old calf. Int. J. Livest. Res., 6(1): 98-103.

11. Mahajan, A., Gupta, A., Bhadwal, M., Bhat, M. and Bhardwaj, H. (2017) Occurrence and management of obstructive urolithiasis in ruminants. J. Anim. Res., 74(4): 723-731.

12. Karras, S., Modransky, P. and Welker, B. (1992) Surgical correction of urethral dilatation in an intersex goat. $\mathrm{J}$. Am. Vet. Med. Assoc., 201(10): 1584-1586.

13. Temizsoylu, M.D. (2005) Penile urethral diverticulum in a kid. Ankara Univ. Vet. Fak. Derg., 52(1): 185-187.

14. Almubarak, A.M., Abdelghafar, R.M., Gameel, A.A. and Osman, N.M. (2016) Penile urethral hypospadias with two fistulae and diverticulum in a Saanen kid. Case Rep. Vet. Med., 2016: 1-3.

15. Bokhari, S. (2013) Hypospadias and urethral diverticulum in two goat kids: A case report. J. Anim. Plant Sci., 23(2): 675-677.

16. Anderson, D., Wallace, C., Williamson, L. and Mahaffey, M. (1993) Urethral recess dilatation in a Charolais-cross bull calf. Can. Vet. J., 34(4): 234-235.

17. Gasthuys, F., Martens, A. and De Moor, A. (1996) Surgical 
treatment of urethral dilatation in seven male cattle. Vet. Rec., 138(1): 17-19.

18. Shiju, S., William, B., Rao, G., Sivashanker, R. and Kumar, S.R. (2010) Congenital malformations in ruminants and its surgical management. Vet. World, 3(3): 1118-1119.

19. Johnson, E., Nyack, B. and Johnson, R. (1980) Urethral dilatation in a steer: A case report. Vet. Med. Small Anim Clin.,75(9): 1429-1431.

20. King, W.W., Young, M.E. and Fox, M.E. (2002) Multiple congenital genitourinary anomalies in a polled goat. J. Am. Assoc. Lab. Anim. Sci., 41(5): 39-42.

21. Sutaria, P., Sutaria, P.T., Patel, J., Patel, A., Patel, P. and Suthar, B. (2018) Modified tube cystotomy for management of obstructive urolithiasis in young male bovines: A review of 9 cases. J. Dairy Vet. Anim. Res., 7(3): 120-123.

22. Kumar, R., Verma, N., Khan, S., Basha, M., Pawde, A.M. and Amarpal, A. (2019) Management of obstructive urolithiasis in a bullock by urethrotomy. J. Pharmacogn. Phytochem., 8(3): 2080-2082.

23. Misk, N.A., Misk, T.N. and Semieka, M.A. (2013) Diagnosis and treatment of affections of the urethra in male ruminants: A review of 403 cases. Int. J. Vet. Med., 2013(2013): 1-10.

24. Van Metre, D.C., House, J.K., Smith, B., Thurmond, M., George, L.W., Angelos, S.M., Angelos, J.A. and Fecteau, G. (1996) Obstructive urolithiasis in ruminants: Surgical management and prevention. Compend. Contin. Educ. Pract. Vet., 18(suppl. 10): 275-289.

25. Sindak, N., Sahin, T. and Biricik, H.S. (2010) Urethral dilatation, ectopic testis, hypoplasia penis, and phimosis in a
Kilis goat kid. Kafkas Univ. Vet. Fak. Derg., 16(1): 147-150.

26. Bayoumi, Y.H. and Attia, N.E. (2017) Comparative study of obstructive urolithiasis and its sequelae in buffalo calves. Vet. World, 10(2): 156-162.

27. Braun, U. (1993) Ultrasonographic examination of the left kidney, the urinary bladder, and the urethra in cows. J. Vet. Med. A, 40(1): 1-9.

28. Cartee, R., Selcer, B. and Patton, C. (1980) Ultrasonographic diagnosis of renal disease in small animals. J. Am. Vet. Med. Assoc., 176(5): 426-430.

29. Magda, M. (2006) Diagnosis of obstructive urolithiasis in cattle and buffalo by ultrasonography. Online J. Vet. Res., 10(1): 26-30

30. Harari, O. (2003) Tube cystotomy for treatment of urethral calculi and obstruction in pet pigs. Isr. J. Vet. Med., 58(4): 109-111.

31. Gandomani, M.J., Nazhvani, S.D. and Jahromi, A.R. (2009) Congenital penile urethral aplasia in a 4-day-old bull calf. Iran. J. Vet. Res., 10(1): 87-89.

32. Marzok, M. and El-Khodery, S. (2013) A comparison of surgical outcomes of perineal urethrostomy plus penile resection and perineal urethrostomy in twelve calves with perineal or prescrotal urethral dilatation. Open Vet. J., 3(2): 106-113.

33. Parsons, D., Lawhorn, B., Walker, M., Edwards, J. and Hague, B. (1998) Incomplete urethral obstruction associated with dilatation of the urethra, cystitis, and pyelonephritis in a Vietnamese pot-bellied pig. J. Am. Vet. Med. Assoc., 212(2): 262-264. 